\title{
Appendicitis Caused by Endometriosis Within the Bowel Wall
}

Anupam K. Gupta ${ }^{1}$, Adam Mann ${ }^{2}$, Avraham Belizon ${ }^{2}$

1. Minimally Invasive Surgery, University of Miami Hospital, Miami, USA 2. General and Colorectal Surgery, Boca Raton Regional Hospital/Florida Atlantic University, Boca Raton, USA

Corresponding author: Anupam K. Gupta, dranupamkumargupta@gmail.com

\begin{abstract}
Acute appendicitis is one of the most common causes of acute abdominal pain seen in the emergency room. Common etiologies include obstructing appendicolith and lymphoid adenopathy. Appendiceal endometriosis is rare and typically involves the serosal layer. This case report describes an unusual case of appendicitis secondary to endometriosis in the musclularis mucosa of the appendix in the 36-year-old lady with no prior history of endometriosis.
\end{abstract}

Categories: Obstetrics/Gynecology, Pathology, General Surgery

Keywords: appendicitis, endometriosis, endometrioma, appendiceal endometriosis

\section{Introduction}

Acute appendicitis is the most common surgical diagnosis of abdominal pain in the right lower quadrant [1]. Endometriosis in the right lower quadrant can mimic acute appendicitis and can deposit into the nearby tissue such as the ovary, fallopian tube, and the appendix [2,3]. Endometrial tissue is in the appendix in $0.4 \%$ of the general population and $2.8 \%$ of patients with previously diagnosed endometriosis [4]. Appendiceal endometriosis most commonly deposits onto the serosal layer of the intestinal wall with occasional involvement of deeper layers [5]. Endometrial tissue in the muscularis propria without any involvement of the serosa layer/surrounding structures causing appendicitis is a histopathological diagnosis we encountered in this case.

Received 05/10/2020

Review began 05/17/2020

Review ended 08/01/2020

Published 08/08/2020

() Copyright 2020

Gupta et al. This is an open access article

distributed under the terms of the

Creative Commons Attribution License

CC-BY 4.0., which permits unrestricted

use, distribution, and reproduction in any

medium, provided the original author and source are credited.

\section{Case Presentation}

A 36-year-old woman with no prior medical history presented to the emergency room with a one-day onset of acute abdominal pain. She had pain and tenderness in the right lower quadrant. On arrival, her vital signs were stable, and clinical examination was positive for pain and tenderness in the right lower quadrant. Blood work showed evidence of leukocytosis of $11.7 \mathrm{k} / \mathrm{ml}$. Computed tomography of the abdomen and pelvis performed in the emergency room showed evidence of a dilated $1.6 \mathrm{~cm}$ retrocecal appendix with periappendiceal inflammatory changes (Figures 1,2). 


\section{Cureus}

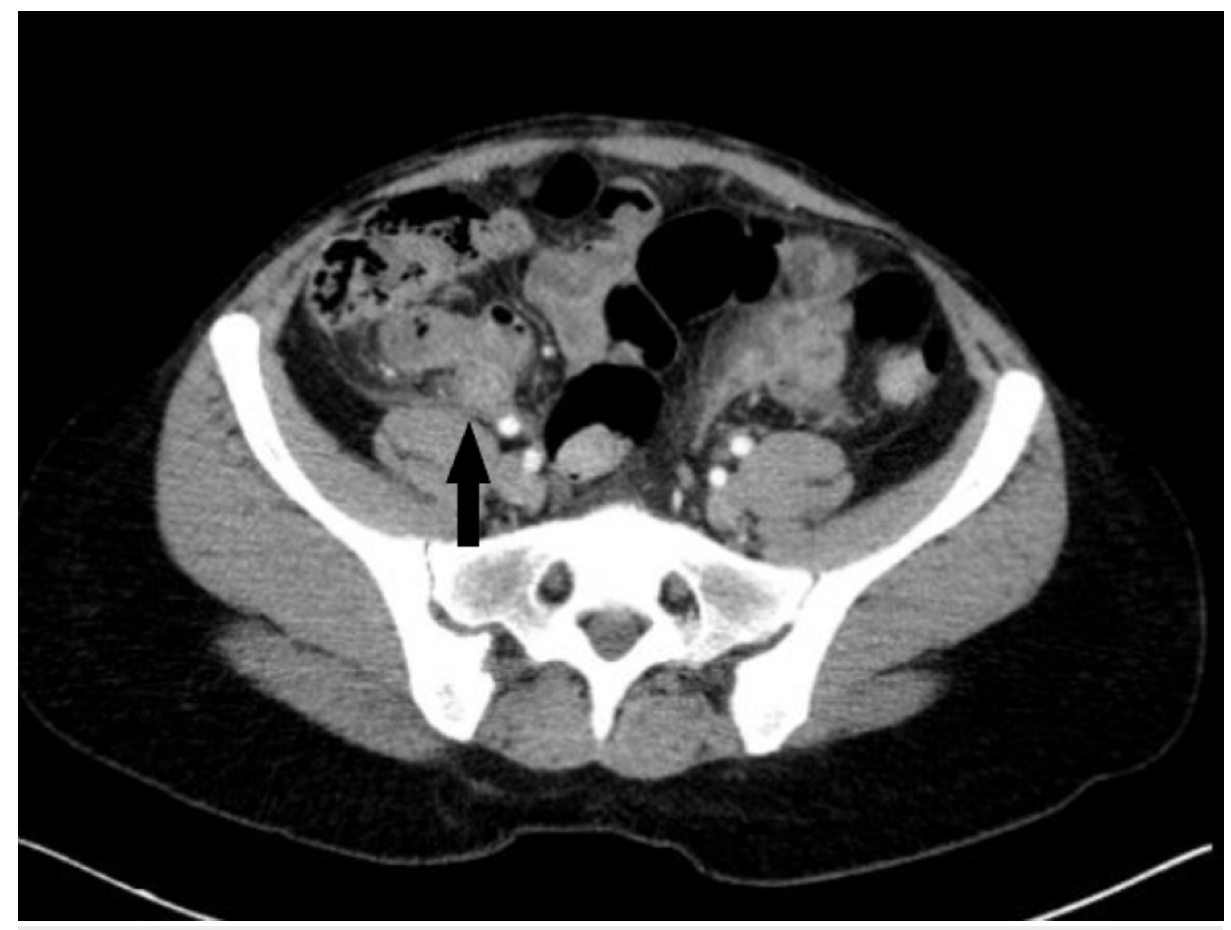

FIGURE 1: Retrocecal inflamed appendix adhered to the cecum 


\section{Cureus}

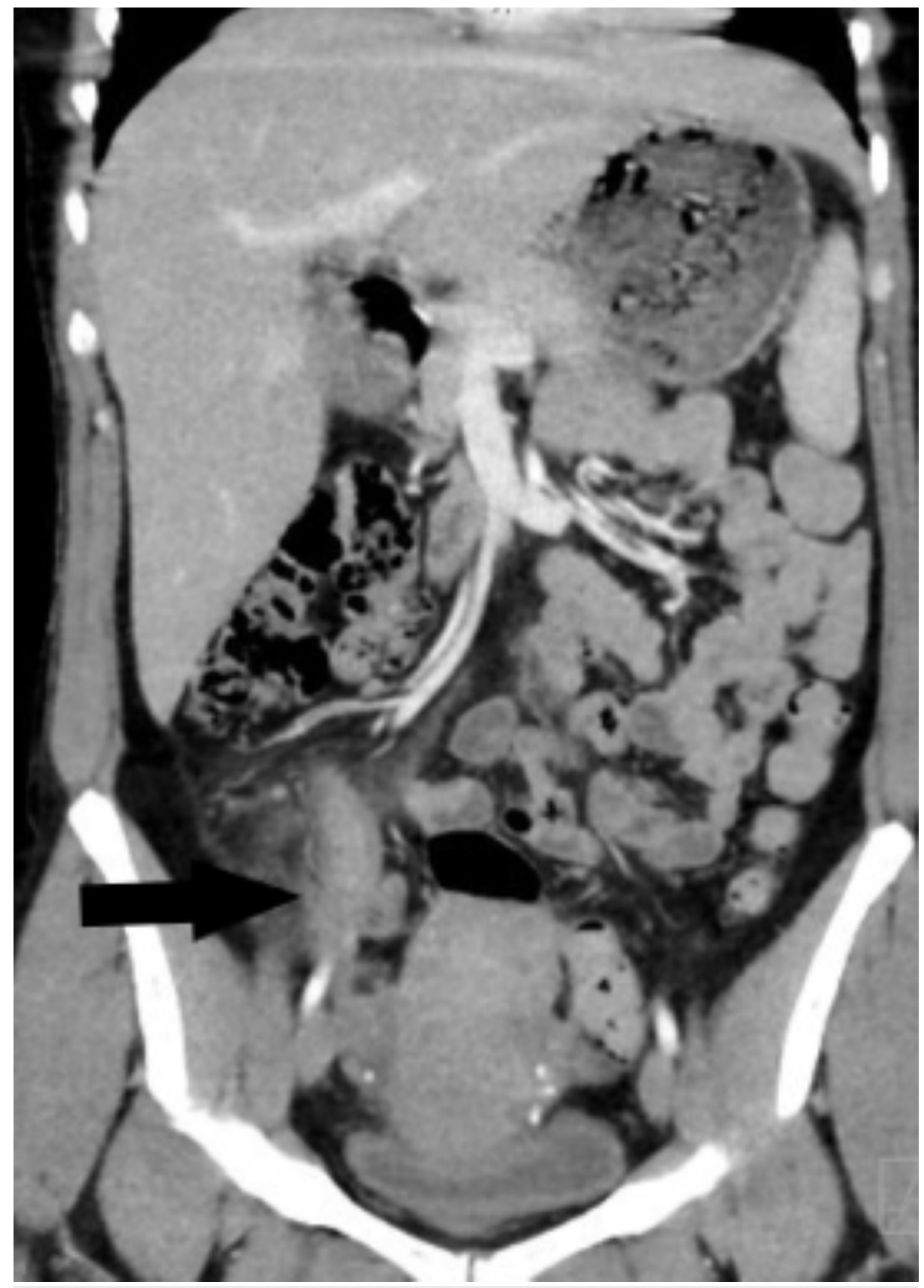

FIGURE 2: $1.6 \mathrm{~cm}$ appendix with periappendiceal inflammatory changes

The patient underwent an emergent laparoscopic appendectomy. In the operating room, the cecum appeared to be edematous and inflamed, and we performed an open ileocecectomy with primary ileocolic anastomosis. The postoperative course was uneventful. On postoperative day two, the patient tolerated a clear liquid diet and on day five postoperative she was discharged from the hospital. Histopathology analysis of the specimen revealed the presence of endometriosis of the muscularis propria of the cecum and the appendix with findings consistent with appendicitis (Figures 3, 4, 5). 


\section{Cureus}

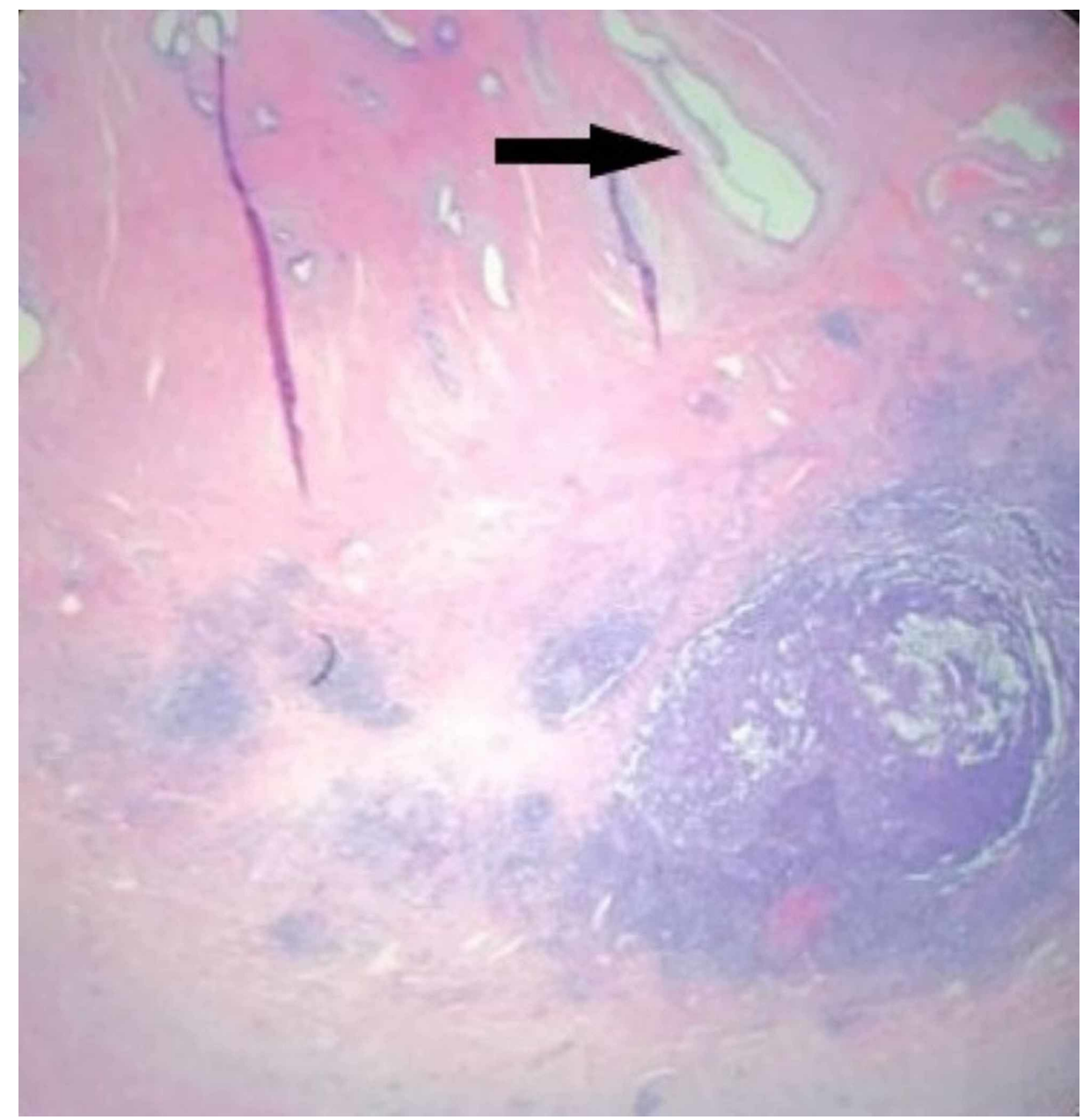

FIGURE 3: Appendix, arrow depicts the endometrial glands and stroma and inflamed lymphoid tissue inferiorly 


\section{Cureus}

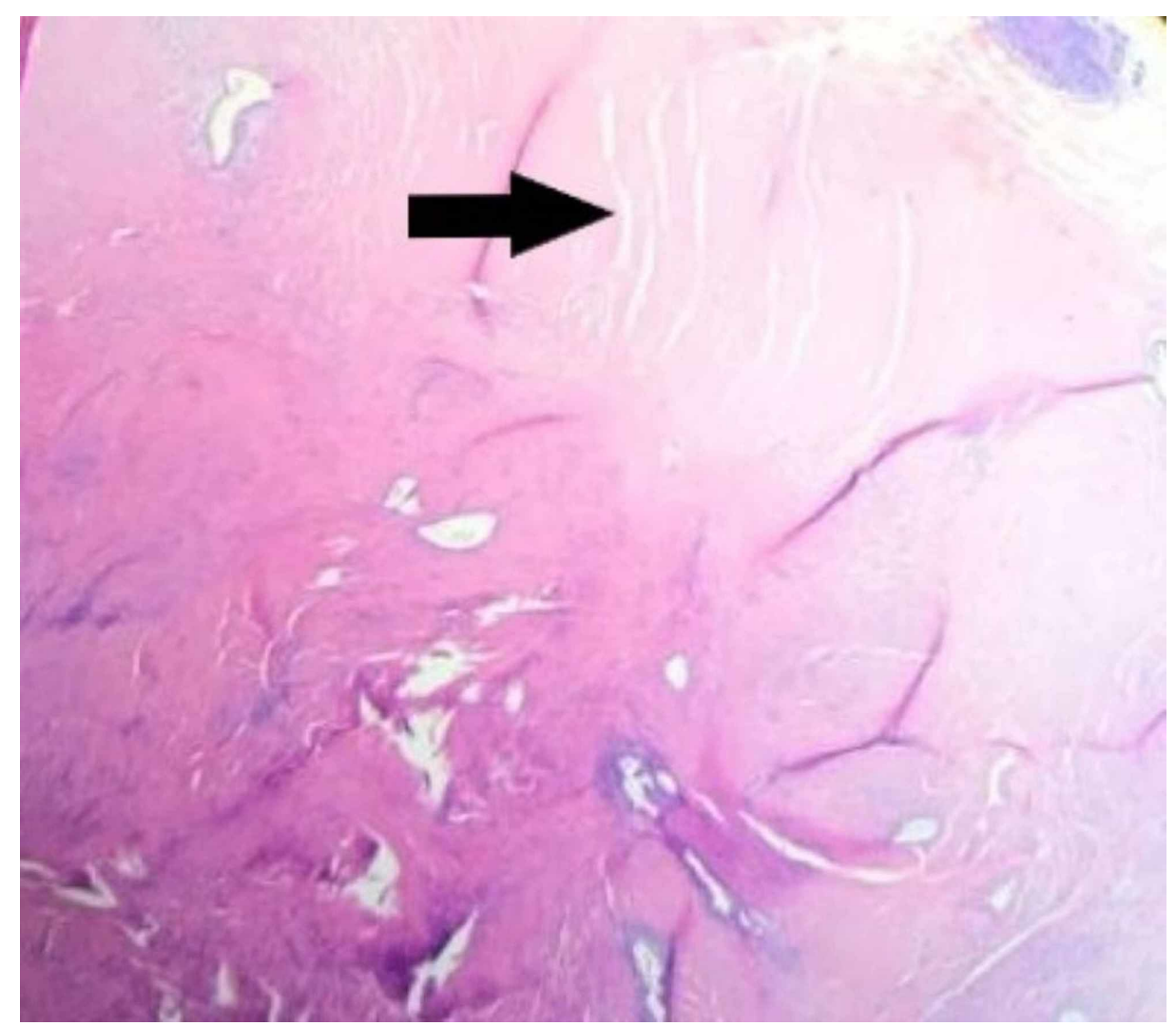

FIGURE 4: Cecal wall. Arrow points to an enlarged muscularis propria with endometrial glands and stroma 


\section{Cureus}

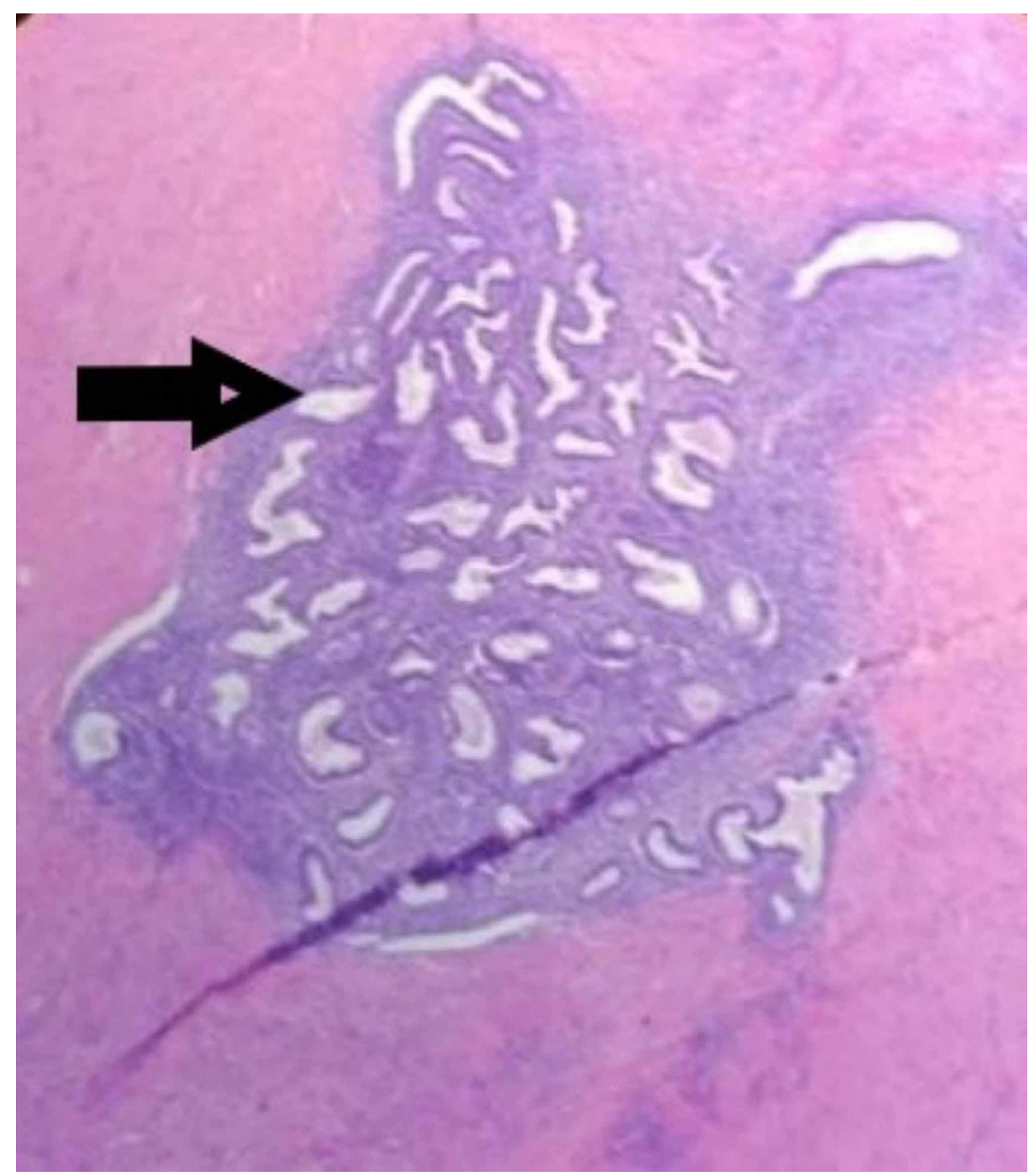

FIGURE 5: Endometrial glands in the muscularis mucosa of the cecum

\section{Discussion}

Endometriosis is a benign disease in females characterized by an abnormal growth of endometrial glands and stroma outside of the uterine cavity. Women of childbearing age can have endometriosis, and this ectopic tissue undergoes normal physiologic response to female reproductive hormones, which can irritate surrounding tissues [6]. The most common sites of endometriosis are the ovaries, fallopian tubes, pelvic peritoneum, cervix, vagina $[2,7,3]$.

There are several hypotheses about the pathogenesis of endometriosis. Retrograde menstruation involves the direct-contact deposition of endometrial tissue into the peritoneal cavity [8]. Retrograde menstruation leads to endometrial tissue seeding directly onto structures nearby the uterus. Coelomic metaplasia is another theory based on the embryonic origin of mesodermal organs such as the intestinal wall and female reproductive organs. Chronic inflammation and irritation of abdominopelvic structures can transform into endometrial tissue of similar embryonic origin. The embryonic rest theory hypothesizes that remnants of mullerian tissue remain in adult organs, and a change in the environment can proliferate cells that resemble fetal tissues $[7,8]$.

Appendiceal endometriosis is present in $0.4 \%$ of the general population and $2.8 \%$ of patients with previously diagnosed endometriosis [9]. Endometrial tissue in the appendix is reported $66 \%$ of the cases in the serosa [9]. The endometrial tissue identified in this case reports exclusive involvement in the muscularis propria of both the appendix and the cecum without serosal deposits. This abnormal growth can progress to acute appendicitis with chronic inflammation caused by the endometrial glands and stroma, causing the development of fibrosis and hypertrophy of the muscularis propria and can wholly or partially occlude the appendiceal lumen [4]. It is unclear how this patient without any previous diagnosis of endometriosis developed endometriosis of the muscularis propria and puts into question the theory of retrograde menstruation as there can be no direct seeding without the involvement of the serosa. The appendix and the 
cecum are both mesodermal tissue, and the transformation of the intestinal wall supports the theory of coelomic metaplasia.

Presentation, diagnosis, and management of this disease are the same as appendicitis of any etiology. Patients will most commonly present with periumbilical pain migrating to the right lower quadrant with associated fevers, nausea, and diarrhea. The diagnosis is clinical; however, adjuncts such as computed tomography, magnetic resonance imaging, and ultrasonography are helpful in appropriate patient populations. The treatment is an appendectomy, and to confirm the diagnosis of appendiceal endometriosis, histopathological analysis of specimen is performed $[10,11]$.

\section{Conclusions}

Endometriosis of the appendix can present with right lower quadrant abdominal pain, which mandates an appendectomy. However, it is unusual to see evidence of endometrial tissue with the involvement of only the muscularis propria of the bowel wall without any previous history of endometriosis involving the abdominal cavity or any findings on the serosal layer. Appendiceal endometriosis is a histopathological diagnosis, and the surgeon should avoid a right hemicolectomy if confused with appendiceal cancer.

\section{Additional Information}

\section{Disclosures}

Human subjects: Consent was obtained by all participants in this study. Conflicts of interest: In compliance with the ICMJE uniform disclosure form, all authors declare the following: Payment/services info: All authors have declared that no financial support was received from any organization for the submitted work. Financial relationships: All authors have declared that they have no financial relationships at present or within the previous three years with any organizations that might have an interest in the submitted work. Other relationships: All authors have declared that there are no other relationships or activities that could appear to have influenced the submitted work.

\section{References}

1. Dahabreh IJ, Adam GP, Halladay CW, et al.: Diagnosis of Right Lower Quadrant Pain and Suspected Acute Appendicitis [Internet]. Agency for Healthcare Research and Quality (US). Brown Evidence-based Practice Center (ed): for Healthcare Research and Quality (US), Rockville (MD); 2015. 157:

2. Adeboye A, Ologun GO, Njoku D, Miner J: Endometriosis of the vermiform appendix presenting as acute appendicitis. Cureus. 2019, 11:e5816. 10.7759/cureus.5816

3. Alimi Y, Iwanaga J, Loukas M, Tubbs RS: The clinical anatomy of endometriosis: a review . Cureus. 2018, 10:e3361. 10.7759/cureus.3361

4. Yoon J, Sang Lee Y, Chang H-S, Park CS: Endometriosis of the appendix. Ann Surg Treat Res. 2018, 87:144147. 10.4174/astr.2014.87.3.144

5. Croom RD 3rd, Donovan ML, Schwesinger WH: Intestinal endometriosis. Am J Surg. 1984, 148:660-667. 10.1016/0002-9610(84)90347-7

6. Eskenazi B, Warner ML: Epidemiology of endometriosis. Obstet Gynecol Clin North Am. 1997, 24:235-258. 10.1016/S0889-8545(05)70302-8

7. Agarwal N, Subramanian A: Endometriosis - morphology, clinical presentations and molecular pathology . I Lab Physicians. 2010, 2:1-9. 10.4103/0974-2727.66699

8. Ijaz S, Lidder S, Mohamid W, Carter M, Thompson H: Intussusception of the appendix secondary to endometriosis: a case report. J Med Case Rep. 2008, 2:12. 10.1186/1752-1947-2-12

9. Gustofson RL, Kim N, Liu S, Stratton P: Endometriosis and the Appendix: a Case Series and Comprehensive Review of the Literature.Fertility and Sterility. Endometriosis. 2005, 86:298-303. 10.1016/j.fertnstert.2005.12.076

10. Gorter RR, Eker HH, Gorter-Stam MA, et al.: Diagnosis and management of acute appendicitis. EAES Consensus Development Conference 2015. Surg Endosc. 2016, 30:4668-4690. 10.1007/s00464-016-5245-7

11. Bhangu A, Søreide K, Di Saverio S, Assarsson JH, Drake FT: Acute appendicitis: modern understanding of pathogenesis, diagnosis, and management. Lancet. 2015, 386:1278-1287. 10.1016/s0140-6736(15)00275-5 